Journal of Clinical Investigation

Vol. 42, No. 2, 1963

\title{
INCREASED SUSCEPTIBILITY TO PYELONEPHRITIS DURING ACUTE HYPERTENSION BY ANGIOTENSIN II AND NOREPINEPHRINE *
}

\author{
By ROGER K. JONES and ALVIN P. SHAPIRO with the technical assistance of \\ ARLENE BLANK AND JEAN SMALL
}

\begin{abstract}
(From the Department of Medicine, University of Pittsburgh School of Medicine,
\end{abstract} Pittsburgh, Pa.)

(Submitted for publication July 23, 1962 ; accepted October 18, 1962)

Chronic pyelonephritis and hypertensive vascular disease often coexist clinically, and a primary and causal role in the relationship usually has been attributed to the renal inflammatory disease. In experimental pyelonephritis, however, where the sequence of events and the presence of other complicating factors can be controlled, such a causal role has not been clearly established. A number of investigators have noted development of hypertension in rats with chronic pyelonephritis, but this has been either mild, of low and irregular incidence, or associated with unilateral nephrectomy, or hydronephrosis, or both (1-3). On the other hand, in our previous studies in rats, in which renal infection was produced by a nonobstructive technique that results in damage to the kidney only by the inflammatory process, chronic pyelonephritis, from any one of several different bacterial species, has not been followed by significant hypertension or vascular disease. Nor have the development of renal failure or the additional insults of infection with a mixed bacterial flora and reduction of renal mass by unilateral nephrectomy produced hypertension in this model $(4,5)$. Such animals, however, do show a greater response than normal rats to the hypertensive influences of salt and desoxycorticosterone (6). Similarly, Guze and Kalmanson have demonstrated the failure of hypertension to develop in rats with chronic nonobstructive pyelonephritis produced by repeated injections of Enterococci alone and with Escherichia coli (7).

Conversely, rats made chronically hypertensive by either renal artery constriction or administra-

\footnotetext{
* Supported by grants from the Health Research and Services Foundation of Allegheny County, Pa., and the U. S. Public Health Service; presented in part at the meetings of the Southern Section of the American Federation for Clinical Research, January, 1962.
}

tion of salt and desoxycorticosterone show a significant increase in susceptibility to pyelonephritis after hematogenous challenge with $E$. coli $(6,8$, 9 ). These studies suggest that pyelonephritis can be a complication rather than a cause of the vascular disease, resulting from increased vulnerability of the hypertensive kidney to infection.

Two different mechanisms have been proposed to explain the vulnerability of chronically hypertensive rats to renal infection: 1) renal damage or metabolic alterations occurring secondarily to hypertension, and 2) changes in renal hemodynamics accompanying hypertension (6). The present investigation was designed to evaluate the effects of hemodynamic changes alone. From study of susceptibility to pyelonephritis during an acute episode of elevated blood pressure, organic changes in the kidney as a result of prolonged hypertension would be unlikely. Angiotensin II and norepinephrine were used for producing such an acute episode. Both are powerful pressor agents. Angiotensin is at least five to ten times more potent than norepinephrine (10), and, in contrast to norepinephrine, has a stronger effect on the visceral blood vessels. Moreover, angiotensin affects primarily the arterial side of the capillary, and has a lesser ability than norepinephrine to constrict veins $(11,12)$. Both pressor agents act briefly, the effect of a single intravenous dose disappearing within a few minutes.

\section{METHODS AND MATERIALS}

A. Angiotensin. ${ }^{1}$ A preliminary evaluation of the effects of angiotensin II in the rat demonstrated that intravenous injection of $10 \mu \mathrm{g}$ into a tail vein elevated systolic blood pressures to an average of $170 \pm 14 \mathrm{~mm} \mathrm{Hg}$ within 30 seconds of injection, with return to normal

${ }^{1}$ As synthetic valyl-5-angiotensin II, supplied by Ciba Pharmaceutical Company, Summit, N. J. 


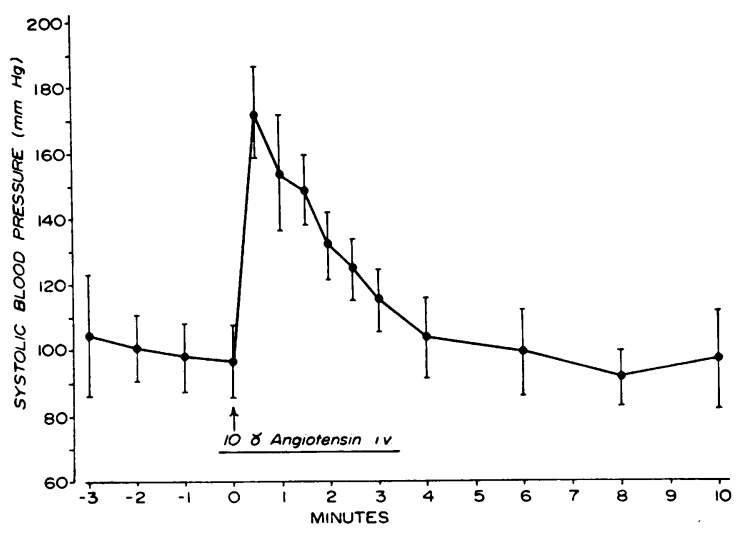

Fig. 1. Response of RAt bloOd pRessures to ANGioTENSIN II. Vertical bars at each interval represent standard deviations of blood pressure response $(n=10)$.

levels within 5 minutes (Figure 1). Blood pressures were measured during light ether anesthesia by the tail phonomicrophone technique, with the Infraton amplifier and recorded on a direct-writing Sanborn electrocardiograph (8). With this technique, repeated blood pressures can be obtained in an intact rat and without arterial cannulation as often as every 20 to 30 seconds. In vivo inspection of the kidneys after i.v. injection of $10 \mu \mathrm{g}$ of angiotensin demonstrated intense renal blanching punctuated by a diffuse, speckled, mottled appearance during the period of maximal hypertension. This reached its peak approximately 90 seconds after injection and was followed by a stage of relative engorgement that gradually diminished over 15 minutes.

Male albino rats of the Carworth strain weighing 250 to $400 \mathrm{~g}$ at the time of testing were used. They were maintained on rat chow and allowed tap water ad libitum. Three groups were studied. Group I (44 rats) received $10 \mu \mathrm{g}$ of angiotensin in $0.5 \mathrm{ml}$ of an 18-hour tryptose broth culture of the strain of $E$. coli used in previous studies $(6,8)$ and containing approximately $10^{8}$ organisms per $\mathrm{ml}$. Group II ( 45 rats) received $0.5 \mathrm{ml}$ of the same culture of $E$. coli without angiotensin, and Group III (16 rats) received $10 \mu \mathrm{g}$ of angiotensin in $0.5 \mathrm{ml}$ of sterile tryptose broth. All inoculations were made by the tail vein. Rats from each group were sacrificed at 1, 4, and 24 hours, 1 and 2 weeks after injection. Blood pressures were determined on all rats within 2 days before injection and on randomly selected rats shortly before sacrifice. Immediately before sacrifice, $1.0 \mathrm{ml}$ of blood was obtained by cardiac puncture for culture. At sacrifice, both kidneys were removed from each rat and divided through their long axis into halves. One portion was immediately fixed in $\mathbf{1 0}$ per cent formaldehyde solution for subsequent histological studies; the other was weighed before being ground to a pulp in sterile water and sea sand. Liver and spleen tissue taken from randomly selected rats of each group were treated similarly. Pour plates were prepared from serial dilutions of tissue homogenates, and numbers of $E$. coli per gram of tis- sue and per milliliter of blood were calculated as described in earlier studies (13). The heart was removed from each animal, trimmed to the ventricles, wrapped in parafilm, and weighed. To maintain a check on the continued virulence of the strain of $E$. coli, normal rats were injected and subjected to gentle renal massage through the intact abdominal wall (13), and the incidence of gross lesions and bacterial counts in the kidneys was noted at 1 week. Growth of $E$. coli after in vitro mixture with varying concentrations of angiotensin was determined and was neither enhanced nor inhibited.

B. Norepinephrine. Blood pressure determinations during intravenous norepinephrine injection were not readily obtained by the tail phonomicrophone technique probably because, in contrast to angiotensin, this drug produces greater decrease in vascular volume in the tail (12). With direct arterial cannulation, however, it has been established that significant increase in blood pressure occurs in rats with doses of norepinephrine as low as $5 \mu \mathrm{g}$ per $\mathrm{kg}$ of body weight (14). In vivo inspection of kidneys after intravenous injection of $10 \mu \mathrm{g}$ of norepinephrine failed to demonstrate the alteration in gross appearance noted after $10 \mu \mathrm{g}$ of angiotensin.

With norepinephrine the same experimental design as with angiotensin was followed, but 1- and 4-hour sacrifice periods were omitted. Three groups of rats again were studied. Group I (28 rats) received $10 \mu \mathrm{g}$ of norepinephrine in $0.5 \mathrm{ml}$ of $E$. coli broth. ${ }^{2}$ Group II (21 rats) received $0.5 \mathrm{ml}$ of $E$. coli only, and Group III (4 rats) received $10 \mu \mathrm{g}$ of norepinephrine in sterile tryptose broth. Liver and spleen cultures were performed on all rats sacrificed at 24 hours. Again, as a "quality control," the incidence of kidney lesions and bacterial counts were determined in groups of rats subjected to injection of E. coli and renal massage. Growth of E. coli in vitro was not altered after mixture with varying concentrations of norepinephrine.

\section{RESULTS}

\section{A. Angiotensin}

Three parameters of renal infection were measured at each sacrifice period: 1) numbers of E. coli per gram of renal tissue, 2) incidence of gross pyelonephritis, and 3) incidence of microscopic pyelonephritic lesions. All organ and blood cultures from Group III animals-those receiving angiotensin only-were sterile, and the kidneys showed no gross or microscopic lesions. Data from Groups I and II follow.

1. Numbers of E. coli per gram of renal tissue. Comparison of the number of $E$. coli per gram of kidney and per milliliter of blood between Group I

2 Three animals in this group received only $1.0 \mu \mathrm{g}$, and two others $5.0 \mu \mathrm{g}$ of norepinephrine. 
and Group II rats is presented in Figure 2. Since these data form a lognormal distribution, the geometric means were calculated and are expressed in the figures and tables as their logarithms. These means, with their appropriate standard errors, were compared by the $t$ test (15). At 1 and 4 hours, both groups of rats had similar numbers of $E$. coli per gram of kidney. At later sacrifice intervals, however-24 hours, 1 , and 2 weeks-, Group I rats had approximately 100 times more E. coli per gram of kidney than Group II rats (logarithm of geometric mean: 5.768 vs 3.811 at 24 hours; 4.554 vs 2.130 at 1 week; and 3.796 vs 1.020 at 2 weeks). ${ }^{3}$ All differences were highly significant $(\mathrm{p}<.001)$. Blood levels of $E$. coli from both groups were closely parallel throughout, indicating that the greater number of bacteria grown in culture from Group I animals was not a reflection of higher blood levels of the organism. In fact, it appeared that bacteria were cleared from the blood slightly faster in Group I rats, although the difference was not significant.

Liver and spleen cultures performed at 24 hours, 1 , and 2 weeks demonstrated essentially identical levels of $E$. coli per gram of tissue in both groups ( $p>.05$ in all instances). Preinjection blood pressures and terminal heart weights in all groups did not differ significantly (Table I). Presacri-

3 The percentages of kidneys in each group revealing any bacteria on culture at these periods were 100 vs 100 at 24 hours; 96 vs 61 at 1 week $(p=.005)$, and 88 vs 35 $(\mathrm{p}<.001)$ at 2 weeks. Even more striking, the percentages of kidneys with bacterial counts of $10^{4}$ or greater were 96 vs 30 at 24 hours $(p<.001), 63$ vs 13 at 1 week $(\mathrm{p}<.001)$, and 46 vs 9 at 2 weeks $(\mathrm{p}=.005)$. For the values at 24 hours, it is important to note that the blood levels of bacteria in both groups were then between $10^{3}$ and $10^{4}$.

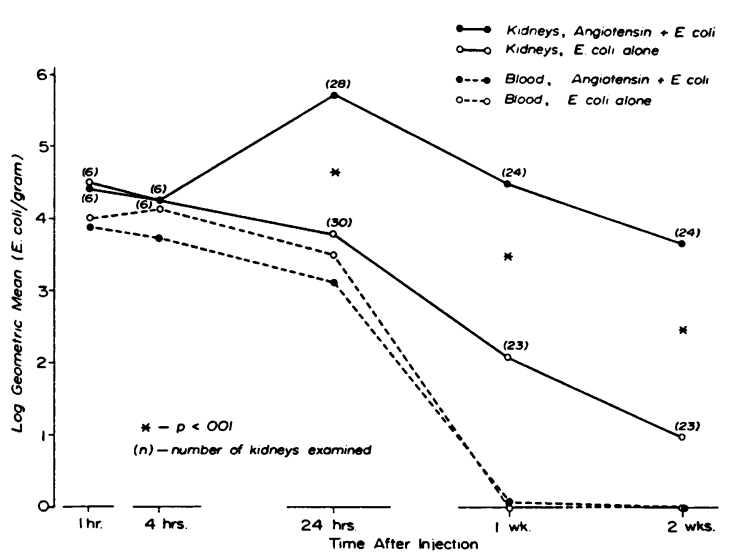

Fig. 2. Kidney and blood levels of E. coli at SACRIFICE IN RATS INOCULATED WITH ANGIOTENSIN AND $E$. coli (Group I) AND IN RATS RECEIVING ONLy E. coli (Group II).

ficial blood pressures on randomly selected rats also were within normal limits in all three groups.

2. Gross incidence of pyelonephritis. At sacrifice all kidneys were carefully examined for evidence of grossly detectable pyelonephritis according to criteria previously described $(4,16)$. No lesions were noted in any animal sacrificed at 1 or 4 hours. At 24 hours, small cortical lesions were noted in 10.7 per cent of kidneys from Group I rats; none were noted in Group II rats. At the end of 1 week 54.2 per cent, and at 2 weeks 66.7 per cent of kidneys from Group I rats were grossly pyelonephritic. At the same periods, only 8.3 per cent of Group II kidneys demonstrated gross evidence of infection (Table II). By the chi square test, significance of the difference at 24 hours was questionable $(p=0.1>.05)$, but at 1 and 2 weeks it was highly significant $(\mathrm{p}=.001)$. Lesions in Group I kidneys were usually multiple, extending throughout cortex and medulla by 1

TABLE I

Blood pressure, heart weight, and bacterial counts in liver and spleen

\begin{tabular}{|c|c|c|c|c|c|c|c|c|c|c|c|c|}
\hline \multirow{3}{*}{$\begin{array}{l}\text { Sacrificial } \\
\text { period }\end{array}$} & \multicolumn{4}{|c|}{ Group I: angiotensin $+E$. coli } & \multicolumn{4}{|c|}{ Group II : E. coli only } & \multicolumn{4}{|c|}{ Group III : angiotensin only } \\
\hline & \multirow{2}{*}{\multicolumn{2}{|c|}{$\begin{array}{l}\text { Systolic } \\
\text { blood Heart } \\
\text { pressure weight }\end{array}$}} & \multicolumn{2}{|c|}{ E. coli per $\mathrm{g}$} & \multirow{2}{*}{$\begin{array}{l}\text { Systolic } \\
\text { blood } \\
\text { pressure }\end{array}$} & \multirow{2}{*}{$\begin{array}{l}\text { Heart } \\
\text { weight }\end{array}$} & \multicolumn{2}{|c|}{ E. coli per $\mathbf{g}$} & \multirow{2}{*}{\multicolumn{2}{|c|}{$\begin{array}{l}\text { Systolic } \\
\text { blood Heart } \\
\text { pressure weight }\end{array}$}} & \multicolumn{2}{|c|}{ E. coli per $\mathrm{g}$} \\
\hline & & & Spleen & Liver & & & Spleen & Liver & & & Spleen & Liver \\
\hline & $m m \mathrm{Hg}$ & $\stackrel{m g /}{100 ~ m l}$ & \multicolumn{2}{|c|}{$\log$ geom. mean } & $m m \mathrm{Hg}$ & $\stackrel{\mathrm{mg} /}{100 \mathrm{ml}}$ & \multicolumn{2}{|c|}{ log geom. mean } & $m m \mathrm{Hg}$ & $\begin{array}{c}m g / \\
100 ~ m l\end{array}$ & \multicolumn{2}{|c|}{$\log$ geom. mean } \\
\hline 1 Hour & 90 & 250 & & & 110 & 249 & & & 120 & 275 & & \\
\hline 4 Hours & 115 & 262 & & & 110 & 243 & & & 105 & 261 & & \\
\hline 24 Hours & 108 & 268 & 6.909 & 6.379 & 112 & 256 & 7.010 & 6.144 & 118 & 263 & $\mathbf{0}$ & $\mathbf{0}$ \\
\hline 1 Week & 107 & 271 & 3.274 & 0 & 115 & 261 & 2.752 & 2.037 & 111 & 254 & $\mathbf{0}$ & $\mathbf{0}$ \\
\hline 2 Weeks & 106 & 247 & 0 & $\mathbf{0}$ & 114 & 251 & 0.319 & 0 & 105 & 244 & $\mathbf{0}$ & $\mathbf{0}$ \\
\hline
\end{tabular}


TABLE II

Effect of angiotensin on percentage of kidneys with pyelonephritic lesions*

\begin{tabular}{|c|c|c|c|c|c|c|}
\hline \multirow[b]{2}{*}{$\begin{array}{l}\text { Sacrificial } \\
\text { period }\end{array}$} & \multicolumn{3}{|c|}{ Gross } & \multicolumn{3}{|c|}{ Microscopic } \\
\hline & $\underset{\text { I }}{\text { Group }}$ & $\underset{\text { II }}{\text { Group }}$ & p & $\underset{I}{\text { Group }}$ & $\begin{array}{l}\text { Group } \\
\text { II }\end{array}$ & $\mathrm{p}$ \\
\hline 24 Hours & 10.7 & 0 & $.1-.05$ & 28.5 & 0 & .002 \\
\hline 1 Week & 54.2 & 8.3 & .001 & 66.5 & 8.3 & $<.001$ \\
\hline 2 Weeks & 66.7 & 8.3 & $<.001$ & 70.5 & 8.3 & $<.001$ \\
\hline
\end{tabular}

* Group I: angiotensin +E. coli. Group II : E. coli alone.

week and progressing to early stages of resolution by 2 weeks. In contrast, the few lesions observed in Group II kidneys were always singular and localized primarily in the renal cortex.

3. Incidence of microscopic pyelonephritis. Microscopic examination of all kidneys confirmed that the gross lesions observed were typical pyelonephritic lesions, similar to those demonstrated in previous experiments and again in this study when intravenous injection and gentle renal massage produced infection. The incidence of microscopic pyelonephritis in both groups also is tabulated in Table II. As with gross observation, no pyelonephritic lesions or other significant pathology was noted at 1 or 4 hours, but at 24 hours 28.5 per cent of Group I kidneys showed microscopic lesions. No evidence of pyelonephritis was demonstrated in Group II at this time $(p=.002)$. At 1 week 66.5 per cent, and at 2 weeks 70.5 per cent of Group I kidneys had microscopic evidence of pyelonephritis, whereas the incidence in Group II kidneys at both periods was 8.3 per cent ( $p<$ $.001)$.

As indicated in Table II, the microscopic examination at 24 hours revealed lesions in Group I kidneys not grossly detectable at this early stage of infection, clearly demonstrating that significant differences between the groups in the incidence of pyelonephritis existed as early as 24 hours after injection. These early lesions, located in both cortex and medulla, consisted of accumulations of bacteria surrounded by polymorphonuclear cells. The data also show that microscopic evidence of pyelonephritis was present in Group I when gross evidence was lacking at 1 and 2 weeks, in contrast to Group II, where gross and microscopic incidences of pyelonephritis were identical at all periods. Furthermore, as expected from the gross appearance of the lesions at 1 and 2 weeks, the histological data indicated that the rare lesions in Group II kidneys were small and showed minimal extension through the kidney parenchyma. whereas lesions in Group I presented the typical wedge-shaped appearance described in previous studies $(13,16)$.

\section{B. Norepinephrine}

All organ and blood cultures from Group III rats-those receiving only norepinephrine-were sterile, and the kidneys demonstrated no pathologic changes. Data from Groups I and II follow.

1. Numbers of E. coli per gram of renal tissue. The number of $E$. coli per gram of kidney and per milliliter of blood in Groups I and II are set forth in Table III. (Data for animals sacrificed at 1 and 2 weeks were combined and considered as a 10-day period for simplicity of presentation, since the results were essentially the same at both periods.) At 24 hours and 10 days, Group I rats had significantly higher levels of $E$. coli per gram of renal tissue than Group II rats. ${ }^{4}$ In contrast to the angiotensin study, the difference was only ten-

${ }^{4} \mathrm{As}$ in the angiotensin experiments, all kidneys in both groups showed some bacteria at 24 hours, when bacteremia was still present. At 10 days, the percentages infected were 67 in Group I vs 27 in Group II $(p<.01)$. Percentages with bacterial counts of $10^{4}$ or greater were 85 vs 35 at 24 hours $(p<.01)$ and 17 vs 0 at 10 days $(\mathrm{p}=.05)$.

TABLE III

Effect of norepinephrine on localization of pyelonephritis*

\begin{tabular}{|c|c|c|c|c|c|c|c|c|c|c|c|}
\hline \multirow[b]{3}{*}{$\begin{array}{l}\text { Sacrificial } \\
\text { period }\end{array}$} & \multirow{2}{*}{\multicolumn{2}{|c|}{$\begin{array}{l}\text { Kidneys } \\
\text { examined }\end{array}$}} & \multicolumn{6}{|c|}{ E. coli per gram } & \multirow{2}{*}{\multicolumn{3}{|c|}{$\begin{array}{c}\text { Kidneys with gross } \\
\text { lesions }\end{array}$}} \\
\hline & & & \multicolumn{3}{|c|}{ Kidney } & \multicolumn{3}{|c|}{ Blood } & & & \\
\hline & $\underset{\text { I }}{\text { Group }}$ & $\underset{\text { II }}{\text { Group }}$ & $\underset{\text { I }}{\text { Group }}$ & $\underset{\text { II }}{\text { Group }}$ & $\mathrm{p}$ & $\underset{\text { I }}{\text { Group }}$ & Group & $\mathrm{p}$ & $\underset{I}{\text { Group }}$ & $\underset{\text { II }}{\text { Group }}$ & p \\
\hline & no. & no. & \multicolumn{3}{|c|}{ log geom. mean } & \multicolumn{3}{|c|}{ log geom. mean } & $\%$ & $\%$ & \\
\hline 24 Hours & 20 & 20 & 4.534 & 3.845 & $<.001$ & 3.447 & 3.460 & $>.05$ & 5.0 & $\mathbf{0}$ & $>.05$ \\
\hline 10 Days & 36 & 22 & 2.512 & 0.914 & $<.01$ & $\mathbf{0}$ & $\mathbf{0}$ & & 30.6 & 4.5 & .015 \\
\hline
\end{tabular}

* Group I: E. coli +norepinephrine. Group II : E. coli alone. 
fold. Blood levels of $E$. coli were virtually identical in both groups at 24 hours and were negative by 1 week. Liver and spleen cultures performed at the 24-hour sacrifice period, terminal heart weights, and preinjection blood pressures again showed no differences between the groups (Table IV).

2. Gross incidence of pyelonephritis. Table III also indicates that at 24 hours, 5 per cent of Group I kidneys had gross lesions, whereas none of Group II kidneys had lesions. This difference was not significant. At the later sacrifice intervals, 30.6 per cent of kidneys from Group I rats demonstrated gross pyelonephritis, in contrast to only 4.5 per cent of kidneys from Group II rats $(\mathrm{p}=.015)$. Only single lesions were observed in Group I kidneys, in contrast to the multiple renal lesions observed in the kidneys of Group I rats in the angiotensin study.

3. Incidence of microscopic pyelonephritis. The gross lesions observed were verified as typical pyelonephritic lesions by microscopic examination of all kidneys. The incidence of microscopic and gross lesions were similar at all sacrifice periods.

\section{Results in rats receiving massage}

Rats who received $E$. coli and renal massage to serve as a check on the virulence of the organism showed a high incidence of pyelonephritis, as in previous studies $(9,12)$. The data from these animals have been combined from both experiments in Table V. The rats sacrificed at 1 week accompanied the angiotensin study, and those at 24 hours and 10 days, the norepinephrine study. These data again confirm the ability of renal massage to localize infection in the kidney. They also indicate that some variation in incidence of infection, even after massage, may occur, so that the type of careful control used in this study is necesary for each experiment.

\section{DISCUSSION}

The data indicate that a brief period of angiotensin-induced hypertension is accompanied by a marked increase in susceptibility to pyelonephritis. Similar results were noted, but to a lesser degree, with norepinephrine. Although changes in renal hemodynamics resulting from elevation

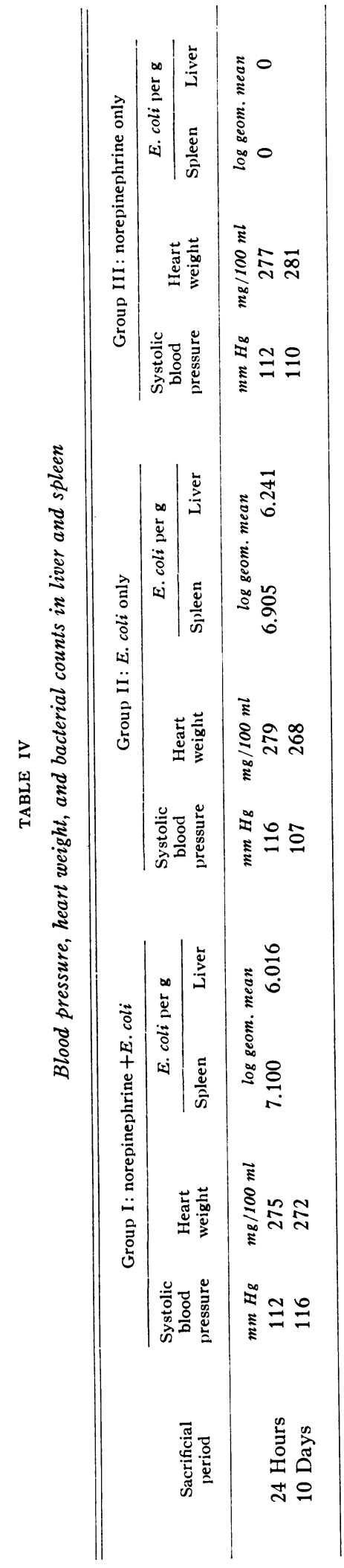


TABLE V

Summary of data in rats receiving $E$. coli and renal massage

\begin{tabular}{|c|c|c|c|c|c|c|c|}
\hline \multirow{2}{*}{$\begin{array}{c}\text { Sacrificial } \\
\text { period }\end{array}$} & \multirow{2}{*}{$\begin{array}{l}\text { No. of } \\
\text { rats }\end{array}$} & \multirow{2}{*}{$\begin{array}{c}\text { Systolic } \\
\text { blood } \\
\text { pressure }\end{array}$} & \multirow{2}{*}{$\begin{array}{l}\text { Heart } \\
\text { weight }\end{array}$} & \multicolumn{2}{|c|}{ E. coli per gram } & \multicolumn{2}{|c|}{ Renal lesions } \\
\hline & & & & Kidney & Blood & Gross & Microscopic \\
\hline & & $m m H g$ & $m g / 100 \mathrm{ml}$ & \multicolumn{2}{|c|}{ log geom. mean } & $\%$ & $\%$ \\
\hline 24 Hours & 5 & 118 & 284 & 7.548 & 4.127 & 0 & 60 \\
\hline 1 Week & 5 & 112 & 245 & 5.543 & 0 & 80 & 80 \\
\hline 10 Days & 8 & 103 & 264 & 5.640 & 0 & 94 & 94 \\
\hline
\end{tabular}

of blood pressure have been suggested in an earlier publication, renal damage secondary to hypertension was considered the most probable cause of the impaired resistance to pyelonephritis noted in chronically hypertensive rats (6). This explanation seems unlikely in the present study, since the duration of elevated blood pressure was much too brief to result in secondary damage, at least of sufficient degree to be detectable histologically.

Although the role of angiotensin in aldosterone production (17-19), the effect of aldosterone on potassium excretion $(18,19)$, and the increase in susceptibility to pyelonephritis in potassium-depleted rats all seem clearly established (20), such a chain of events to account for the present findings seems improbable. The duration of angiotensin effect was brief. Moreover, angiotensin appears to have insignificant steroidogenic potency in the rat (21). Finally, increased susceptibility to pyelonephritis with potassium depletion appears to depend on the production of tubular damage, which requires prolonged deprivation of this electrolyte $(20,22)$. In addition, the enhancement of susceptibility by norepinephrine could not be explained on the basis of electrolyte change.

A hemodynamic mechanism for altered susceptibility is supported by studies of the effect of angiotensin on renal blood flow. Barer (10) noted that in the anesthesized cat, renal blood flow is reduced by both intravenous and intra-arterial injection of angiotensin and that the time course of flow reduction was usually similar to that of the blood pressure changes. During angiotensin infusion studies in man, other investigators have regularly observed an increased intraglomerular pressure and reduced renal blood flow (23).

In rats, infusion of angiotensin reduces renal blood flow and increases vascular resistance; indeed, the kidney is the only organ in this species that consistently demonstrates a diminished flow, whereas in the brain, heart, and lungs it may be unchanged or even increased (24). This was demonstrated clearly in our studies by the direct observation of the blanching of the kidney at the height of blood pressure elevation. A period of engorgement followed this episode of blanching.

It seems clear, therefore, that angiotensin has a profound effect on renal blood flow. Norepinephrine acts similarly on the kidney, but to a lesser extent, as indicated both by our observations that blanching of the kidney was not seen grossly with $10 \mu \mathrm{g}$ of norepinephrine and by evidence that its effect is more generalized and proportionately greater than that of angiotensin in peripheral areas such as muscle $(11,12)$. Decreased renal flow and increased resistance with norepinephrine have been shown by Mehrizi and Hamilton to result in a delayed transit time of blood through the kidney (25). Angiotensin, with its even more marked hemodynamic effects on the kidney, presumably would produce a similar delay in transit time. This was suggested visually in the present study by the period of engorgement observed after the initial blanching after angiotensin injection. Other possible consequences of the acute hemodynamic changes that might play a role are anoxic injury to vascular epithelium that could permit escape of bacteria to interstitial sites and increased hydrostatic forces that might influence bacterial transudation. In any case, these various mechanisms could result in "trapping" of bacteria in the kidney for a long enough period to allow them to begin to propagate and establish infection.

Although no differences in numbers of bacteria per gram of kidney were demonstrated at 1 or 4 hours after inoculation, or long after return of grossly normal appearance of the kidney in the rats receiving the $E$. coli-angiotensin mixture, the 
bacteremia then present may have obscured small differences in renal bacterial counts. By 24 hours, when bacteremia had decreased in intensity, a difference was clearly demonstrated. Indeed, the slightly more rapid clearance of bacteria from the blood in the animals with $E$. coli-angiotensin would favor the concept of renal trapping, as does the demonstration that norepinephrine, which obviously disturbed renal hemodynamics less, had lesser effects on altering renal bacterial levels and susceptibility to infection.

This study has demonstrated that a change in renal blood flow, rather than elevation of blood pressure itself, has enhanced vulnerability of the rat kidney to infection. However, inasmuch as this type of renal vascular change usually is associated with a pressor stimulus, the findings have pertinence to hypertensive states. Moreover, that endogenously available vasoconstrictor materials can result in increased vulnerability to renal infection is an observation that alone has implications in the pathogenesis of hematogenous pyelonephritis.

\section{SUMMARY}

An acute episode of hypertension was produced in rats by intravenous injections of angiotensin or norepinephrine. In rats that received $E$. coli with the vasoconstrictor agent, pyelonephritis was exhibited to a significantly greater extent than in rats challenged with $E$. coli only. The short duration of the hypertension produced indicates that alterations in renal blood flow may be the important factor in the previously observed vulnerability of hypertensive rats to pyelonephritis.

\section{ACKNOWLEDGMENT}

The assistance of Dr. Mindel Sheps, Department of Biostatistics, Graduate School of Public Health, University of Pittsburgh, in the statistical analyses is gratefully acknowledged.

\section{REFERENCES}

1. Spitznagel, J. K., and Schroeder, H. A. Experimental pyelonephritis and hypertension in rats. Proc. Soc. exp. Biol. (N. Y.) 1951, 77, 762.

2. Vivaldi, E., Zangwill, D. P., Cotran, R., and Kass, E. H. Experimental pyelonephritis consequent to induction of bacteriuria in Biology of Pyelonephritis, Henry Ford Hospital International Symposium, E. L. Quinn and E. H. Kass, Eds. Boston, Little, Brown, 1960, p. 27.
3. Heptinstall, R. H. Experimental pyelonephritis. The effect of chronic infection on the blood pressure in the rat. Brit. J. exp. Path. 1962, 43, 333.

4. Shapiro, A. P., Braude, A. I., and Siemienski, J. Hematogenous pyelonephritis in rats. IV. Relationship of bacterial species to the pathogenesis and sequelae of chronic pyelonephritis. J. clin. Invest. 1959, 38, 1228.

5. Shapiro, A. P., and Kobernick, J. L. Effects of unilateral nephrectomy and mixed infection on blood pressure of rats with experimental chronic pyelonephritis. Circulat. Res. 1959, 7, 936.

6. Shapiro, A. P., and Kobernick, J. L. Susceptibility of rats with renal hypertension to pyelonephritis, and predisposition of rats with chronic pyelonephritis to hormonal hypertension. Circulat. Res. 1961, 9, 869.

7. Guze, L. B., and Kalmanson, G. M. Pyelonephritis. III. Observations on the association between chronic pyelonephritis and hypertension in the rat. Proc. Soc. exp. Biol. (N. Y.) 1961, 108, 496.

8. Shapiro, A. P. Susceptibility of rats with DCA hypertension to experimental pyelonephritis and aggravation of DCA hypertension by renal infection. J. Lab. clin. Med. 1960, 55, 715.

9. Woods, J. W. Susceptibility of rats with hormonal hypertension to experimental pyelonephritis. J. clin. Invest. 1958, 37, 1686.

10. Barer, G. R. A comparison of the circulatory effects of angiotensin, vasopressin and adrenaline in the anaesthetized cat. J. Physiol. (Lond.) 1961, $156,49$.

11. Bock, K. D., Krecke, H.-J., and Kuhn, H. M. Untersuchungen über die Wirkung von Synthetischem Hypertensin II auf Blutdruck, Atmung und Extremitätendurchblutung des Menschen. Klin. Wschr. 1958, 36, 254.

12. Haddy, F. J., Molnar, J. I., Borden, C. W.. and Texter, E. C., Jr. Comparison of direct effects of angiotensin and other vasoactive agents on small and large blood vessels in several vascular beds. Circulation 1962, 25, 239.

13. Braude, A. I., Shapiro, A. P., and Siemienski, J. Hematogenous pyelonephroitis in rats. I. Its pathogenesis when produced by a simple new method. J. clin. Invest. 1955, 34, 1489.

14. Daniel, E. E., Dawkins, O., and Hunt, J. Selective depletion of rat aorta potassium by small pressor doses of norepinephrine. Amer. J. Physiol. 1957, 190, 67.

15. Bernstein, L., and Weatherall, M. Statistics for Medical and Other Biological Students. Edinburgh, E. and S. Livingstone, 1952, pp. 52, 121.

16. Braude, A. I., Shapiro, A. P., and Siemienski, J. Hematogenous pyelonephritis in rats. III. Relationship of bacterial species to the pathogenesis of acute pyelonephritis. J. Bact. 1959, 77, 270.

17. Tobian, L. Interrelationship of electrolytes, juxtaglomerular cells and hypertension. Physiol. Rev. 1960, 40, 280. 
18. Laragh, J. H., Angers, M., Kelly, W. G., and Lieberman, S. Hypotensive agents and pressor substances. The effect of epinephrine, norepinephrine, angiotensin II, and others on the secretory rate of aldosterone in man. J. Amer. med. Ass. 1960, 174, 234.

19. Genest, J. Angiotensin, aldosterone and human arterial hypertension. Canad. med. Ass. J. 1961, 84, 403.

20. Woods, J. W., Welt, L. G., Hollander, W., Jr., and Newton, M. Susceptibility of rats to experimental pyelonephritis following recovery from potassium depletion. J. clin. Invest. 1960, 39, 28.

21. Farrell, G., and Taylor, A. N. Neuroendocrine aspects of blood volume regulation in Annual Review of Physiology, V. E. Hall, F. A. Fuhrman, and
A. C. Giese, Eds. Palo Alto, Annual Reviews, 1962, p. 471.

22. Oliver, J., MacDowell, M., Welt, L. G., Holliday, M. A., Hollander, W., Jr., Winters, R. W., Williams, T. F., and Segar, W. E. The renal lesions of electrolyte imbalance. I. The structural alterations in potassium-depleted rats. J. exp. Med. 1957, 106, 563.

23. Page, I. H., and Bumpus, F. M. Angiotensin. Physiol. Rev. 1961, 41, 331.

24. Mandel, M. J., and Sapirstein, L. A. Effect of angiotensin infusion on regional blood flow and regional vascular resistance in the rat. Circulat. Res. 1962, 10, 807.

25. Mehrizi, A., and Hamilton, W. F. Effect of levarterenol on renal blood flow and vascular volume in dogs. Amer. J. Physiol. 1959, 197, 1115.

\section{SPECIAL NOTICE TO SUBSCRIBERS}

Post Offices will no longer forward the Journal when you move.

Please notify The Journal of Clinical Investigation, Business Office, 10 Stoughton Street, Boston 18, Mass., at once when you have a change of address, and do not omit the zone number if there is one. 